\title{
Tecnologias digitais da informação e comunicação no contexto educação física escolar: análises sobre as abordagens Instrucionistas e Construcionistas
}

\author{
Digital technology of information and communication in the school physical education context: \\ analysis on Instructionist and Constructionist approaches \\ Las tecnologías digitales de la información y la comunicación en el contexto de la educación física \\ escolar: análisis de los enfoques Instruccional y Construccionista
}

João Paulo de Oliveira Faria ORCID: https://orcid.org/0000-0002-7008-8568 Universidade Federal Fluminense, Brasil E-mail: jpfaria25@hotmail.com

Geórgia Regina Rodrigues Gomes ORCID: https://orcid.org/0000-0003-0907-9838 Universidade Federal Fluminense, Brasil E-mail: georgiagomes@id.uff.br

Matheus Carvalho do Nascimento ORCID: https://orcid.org/0000-0002-0041-142X Universidade Federal Fluminense, Brasil E-mail: matheuscn@id.uff.br

\begin{abstract}
Resumo
As Tecnologias Digitais da Informação e Comunicação (TDIC's) tem influenciado significativamente a maneira como a escola tem construído as suas práticas pedagógicas. Em especial neste cenário, o Componente Curricular denominado "Educação Física" pôde reorganizar e fomentar novas formas de trabalhar as práticas corporais no contexto educacional. Este trabalho descreve as contribuições de uma proposta em que a tecnologia é pensada como dispositivo didático nas escolas, com o objetivo de propor reflexões sobre as diferentes possibilidades que as (TIDC's) oferecem para as aulas de Educação Física (EFI) no Ensino Médio. Tratou-se de estudo de caso, em que 35 Estudantes de um Curso de Licenciatura em EFI construíram e analisaram sequências didáticas permeadas por diferentes formas de utilização das tecnologias educacionais pautadas nas abordagens instrucionistas e construcionistas da informática na educação. O estudo esclarece que os métodos instrucionistas na EFI reforçam o caráter tecnicista, mecanicista e técnico do movimento humano, enquanto os métodos construcionistas direcionam-se para aulas com metodologias ativas e mais significativas. Nesta segunda abordagem o professor ganha status de mediador do conhecimento abrindo possibilidade para a construção de práticas pedagógicas mais autônomas e colaborativas. Por fim, esclarece que as 06 (seis) unidades temáticas apresentadas pela Base Nacional Comum Curricular (BNCC) poderão se beneficiar com perspectivas pedagógicas mais críticas e multiculturalistas no contexto da EFI nas escolas.

Palavras-chave: Digitais da Informação e Comunicação (TDIC’s); Educação física; Práticas corporais; Abordagens instrucionistas e construcionistas.

Abstract

Digital Information and Communication Technologies (TDIC) have significantly influenced the way in which the school has built its pedagogical practices. Especially in this scenario, the Curriculum Component called "Physical Education" was able to reorganize and foster new ways of working with bodily practices in the educational context. This work describes the contributions of a proposal in which technology is thought of as a didactic device in schools, with the aim of proposing reflections on the different possibilities that the (TIDC) offer for Physical Education (PE) classes in high school. It was a case study, in which 35 Students of a Licentiate Course in PE built and analyzed didactic sequences permeated by different ways of using educational technologies based on instructional and constructionist approaches to information technology in education. The study clarifies that instructional methods in PE reinforce the technicist, mechanistic and technical character of human movement, while constructionist methods are directed towards classes with active and more significant methodologies. In this second approach, the teacher gains the status of mediator of knowledge, opening the possibility for the construction of more autonomous and collaborative pedagogical practices. Finally, it clarifies that the 06 (six) thematic units presented by the Common National Curriculum Base (in Portuguese, BNCC) may benefit from more critical and multiculturalist pedagogical perspectives in the context of PE in schools.
\end{abstract}


Keywords: Digital Information and Communication Technologies (TDIC); Physical education; Body practices; Instructional and constructionist approaches.

\section{Resumen}

Las Tecnologías Digitales de la Información y la Comunicación (TDIC's) han influido significativamente en la forma en que la escuela ha construido sus prácticas pedagógicas. Especialmente en este escenario, el Componente Curricular denominado "Educación Física" ha sido capaz de reorganizar y promover nuevas formas de trabajar las prácticas corporales en el contexto educativo. Este trabajo describe los aportes de una propuesta en la que se piensa en la tecnología como dispositivo didáctico en las escuelas, con el objetivo de proponer reflexiones sobre las diferentes posibilidades que las (TIDC's) ofrecen a las clases de Educación Física (EFI) en la Escuela Secundaria. Se trata de un estudio de caso en el que 35 alumnos de un curso de Licenciatura en Educación Física construyeron y analizaron secuencias didácticas impregnadas de diferentes formas de uso de las tecnologías educativas a partir de los enfoques instruccional y construccionista de las tecnologías de la información en la educación. El estudio aclara que los métodos instruccionales en IET refuerzan el carácter tecnicista, mecanicista y técnico del movimiento humano, mientras que los métodos construccionistas se dirigen a clases con metodologías activas y más significativas. En este segundo enfoque, el profesor adquiere la condición de mediador del conocimiento, abriendo la posibilidad de construir prácticas pedagógicas más autónomas y colaborativas. Finalmente, aclara que las 06 (seis) unidades temáticas presentadas por la Base Nacional Común Curricular (BNCC) pueden beneficiarse de perspectivas pedagógicas más críticas y multiculturalistas en el contexto de la EFI en las escuelas.

Palabras clave: Tecnologías Digitales de la Información y la Comunicación (TDIC’s); Educación física; Prácticas corporales; Enfoques instruccionales y construccionistas.

\section{Introdução}

A Educação Física trata-se de uma área de conhecimento que, pedagogicamente, se caracteriza por tematizar a “cultura corporal de movimentos". Ela se configura em uma proposta que tematiza os conteúdos baseados nas seguintes práticas corporais: brincadeiras e jogos, esportes, ginásticas, danças, lutas e práticas de aventuras (Silva, 2020).

As práticas corporais nas aulas de EFI, a partir de uma abordagem culturalista, necessitam ser tematizadas para que diferentes assuntos e conhecimentos sejam socializados, debatidos, vivenciados, experimentados e questionados pelos estudantes que se tornam capazes de refletir criticamente sobre o movimento corporal enquanto objeto de linguagem e expressão (Betti, 2007).

Ainda sobre a perspectiva multiculturalista e os desdobramentos sobre a influência da mídia e da tecnologia nas aulas de Educação Física é possível dialogar com Neira (2019) onde se reconhece o movimento humano como fruto de uma essência cultural, dinâmica e viva. As práticas corporais ganham muito mais sentido quando o celular, a televisão ou o computador emanam informações que vão além do senso comum ou das referências exclusivas do professor/treinador. Nesta perspectiva, os currículos tradicionais, hegemônicos e esportivistas são confrontados e questionados, pois o acesso à diferentes informações e conhecimentos auxiliam na tematização mais aprofundada de diferentes práticas corporais contemporâneas.

Apoiados nas ideias de Faria (2020, p.16), tais argumentações ganham sentido corroborando com as informações a seguir:

Os diálogos em EFI são atravessados hoje pelas intercorrências e informações constantes da internet e dos ambientes cibernéticos que colaboram para a construção e a produção das práticas corporais na atualidade. As "linguagens tecnológicas" pertencem ao universo juvenil deste século, sendo assim, pensar, produzir, refletir e vivenciar práticas corporais nas aulas de EFI também por meio dos universos digitais (tecnologia, computador, aplicativos, internet etc.) é uma nova forma de ser e estar no mundo da cultura corporal".

Atrelado a esta perspectiva, Silva (2020) diz que a tecnologia se apoia em um conjunto de recursos que auxiliam no planejamento das atividades de EFI, por meio da construção e a utilização de um equipamento em determinada sequência de objetivos a serem cumpridos. Dentre este planejamento, as TDIC's interferem diretamente na interação dos grupos organizados, a fim de promover um aprendizado mais eficaz baseado na pesquisa e aperfeiçoamento de técnicas aplicadas. Nas 
palavras de Soares e Prado (2020), as tecnologias propiciam a utilização de novas metodologias que permitem o avanço das estratégias de interação e a ação corporal. Por esta atribuição é que nos últimos anos a EFI junto à tecnologia pode adotar um conjunto de métodos e práticas significativas para construir práticas pedagógicas mediadas pelas TDIC's. Neste cenário, a literatura atual apresenta como fundamentação pedagógica os estudos sobre as Abordagens pedagógicas Instrucionistas e Construcionistas no contexto educacional.

Ainda neste contexto, Farias e Impolcetto (2020), traz à baila o fato de que um dos desafios dos professores de EF neste cenário atual situa-se na necessidade de se reconhecerem didaticamente perante as TDIC's, pois as contribuições das tecnologias digitais estão sinalizadas como significativas no ensino das práticas corporais. Todavia, diante deste cenário há conflitos latentes e certa resistência por parte de alguns docentes, entendendo que os ambientes virtuais, a cibercultura e a informática educacional podem representar uma possível perda do "status quo" ou até mesmo uma substituição da mão de obra destes profissionais. Cabe ressaltar que, a formação docente, a atualização profissional e o trabalho com abordagens pedagógicas menos procedimentais poderão ser estratégias valiosas para a abertura das mediações pedagógicas subsidiadas pelas TDIC's.

Antes só o professor ditava como seria o movimento, hoje isto já não basta. A tecnologia pode servir para instruir e para construir novas formas de pensar o movimento humano. Dentro de um processo didático-pedagógico o computador, a informática e as tecnologias podem se apresentar a partir de duas grandes abordagens pedagógicas: a perspectiva Instrucionista e a Construcionista (Papert, 1994).

Mais especificamente, a abordagem instrucionista é baseada em uma série de informações passadas aos alunos por tutoriais, exercícios baseados em tentativa e erro ou jogos. Este sistema didático é construído em torno de perguntas e respostas no sentido de verificar se a informação foi interpretada e assimilada pelo estudante (Silva, 2020). A tarefa principal é administrar o processo de ensino executado por um instrumento de execução de tarefas, como o computador, livrando o professor da atividade de correção contínua de provas ou exercícios.

Por outro lado, o modelo construcionista tem por objetivo fazer com que o aluno construa algo que possua o interessem torno de uma aprendizagem significativa. De forma complementar, a tecnologia é entendida como um meio de comunicação que existe entre o conhecimento, o educador e o aluno. Então, este modelo didático se caracteriza como o:

(...) conjunto de conhecimentos e princípios científicos que se aplicam ao planejamento, à construção e à utilização de um equipamento em um determinado tipo de atividade, chamamos de "tecnologia". Para construir qualquer equipamento - uma caneta esferográfica ou um computador -, os homens precisam pesquisar, planejar e criar o produto, o serviço, o processo. Ao conjunto de tudo isso, chamamos de tecnologias (Kenski, 2012, p. 24).

Com o advento das tecnologias da comunicação houve o incremento de recursos como os computadores e/ou smartphones que são apontados como potencialidades para auxiliar o processo de ensino (Machado, 2020). Desta forma, os estudos de Macedo e Neves (2021) afirmam que a importância da utilização das tecnologias digitais no contexto do ensino da EFI escolar se fundamenta por: tornarem as aulas mais atrativas, evitarem a mera repetição de movimentos, contextualizarem as práticas corporais, além de estimular um pensar interdisciplinar e transversal dentro do cenário do movimento humano sistematizado ou assistemáticos.

Desta forma, este trabalho procura responder as seguintes questões: em que as tecnologias da informação poderiam beneficiar o ensino da EFI? Quais as principais diferenças didáticas observadas pelas abordagens instrucionistas e construcionistas para o ensino das práticas corporais?

Para contextualizar e buscar os apontamentos sobre o tema, a pesquisa se sustenta a partida percepção de Estudantes de um Curso de Licenciatura em EFI sobre os principais conteúdos e práticas pedagógicas que, mediadas pelas as TIDC's na 
EFI, poderão apresentar resultados importantes para fundamentar a utilização das tecnologias educacionais neste cenário, tanto pela proposta instrucionista quanto à construcionista.

Este estudo apresenta dados oriundos da dissertação de Mestrado realizada no âmbito do programa de Pós-graduação em Ensino da Universidade Federal Fluminense (UFF) denominado: Práticas pedagógicas mediadas pelas tecnologias: propostas e desafios no contexto da educação física escolar- que, por sua vez, procurou discutir a proposta da aplicação da tecnologia, a informática e os ambientes cibernéticos; como dispositivos que atravessam a educação física escolar na contemporaneidade.

\section{Metodologia}

A metodologia adotada neste estudo foi à pesquisa descritiva, que segundo Gomes (2008) é uma importante estratégia metodológica para a pesquisa em ciências humanas, pois permite ao investigador um aprofundamento em relação ao fenômeno. Tal metodologia serviu como base ao estudo de caso realizado em um curso de Licenciatura em Educação Física (EFI) -para uma análise de propostas pedagógicas com foco na tecnologia na educação. O estudo delimitou-se em uma coleta de informações acerca da Tecnologia nas aulas de EFI, envolvendo 35 estudantes do $4^{\circ}$ Período de um Curso de Licenciatura em EFI, na cidade de Itaperuna (RJ).

A ideia central se voltou para construção e análise pedagógica coletiva de sequência didáticas envolvendo os 06 (seis) eixos temáticos centrais da EFI escolar, sendo: Jogos e Brincadeiras, Lutas, Danças, Ginásticas, Esportes e Esportes de Aventura.

As Práticas pedagógicas foram elaboradas com base nas possibilidades que as TDIC's oferecem para a tematização e a construção de um ambiente mais interativo para se pensar o movimento como linguagem e cultura. As sequências didáticas abriram espaço para compreender as possibilidades que a informática, a tecnologia e os ambientes da cibercultura poderão oferecer às aulas de EFI no Ensino Médio. O fluxograma desta pesquisa encontra-se ilustrado na Figura 1, da seguinte forma:

Figura 1. Método de pesquisa adotado.

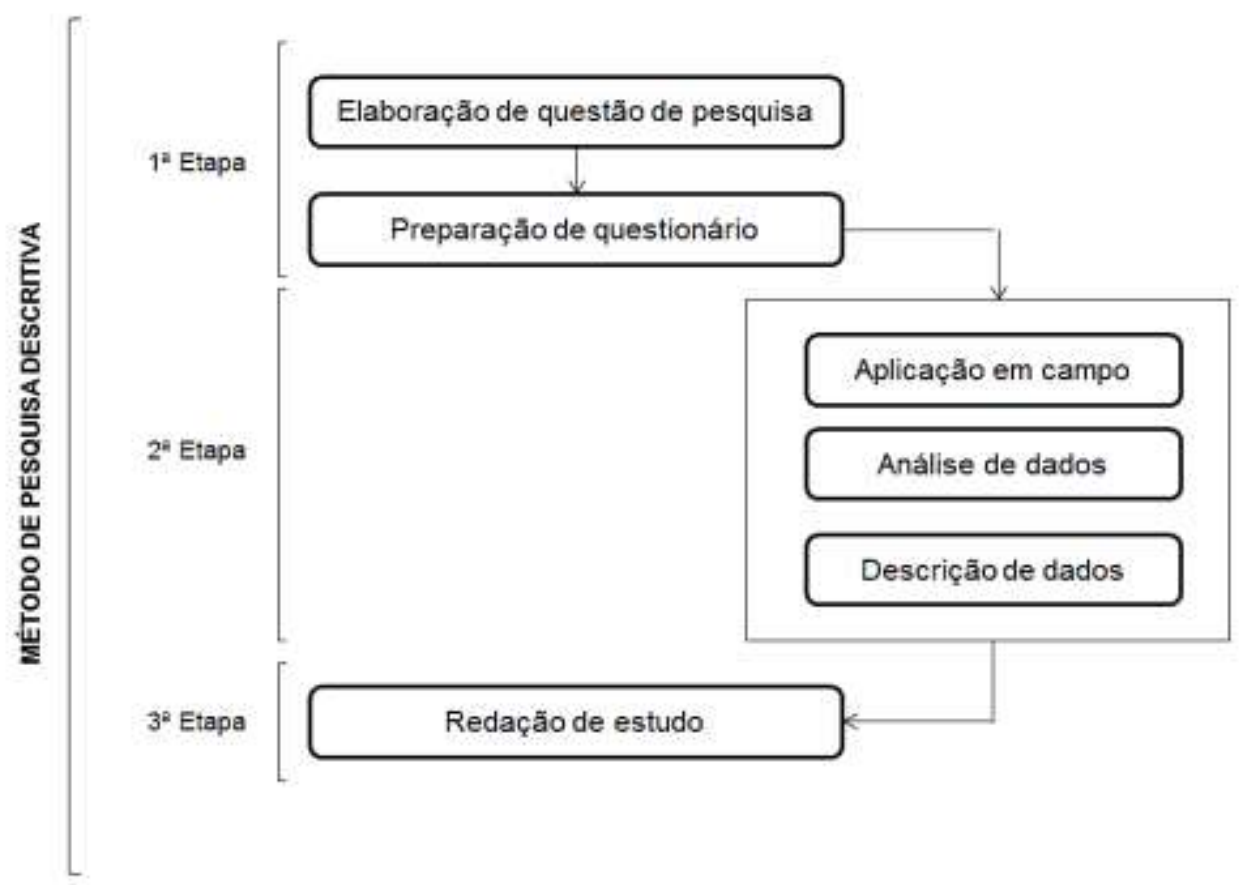

Fonte: Autores (2020). 
O questionário foi construído com recursos disponíveis no Google Forms, sendo este, um recurso de armazenamento e sincronização de arquivos, proposto pela Google, com aplicações de produtividade, edição de documentos, folhas de cálculo, apresentações de gráficos etc. Este recurso tecnológico foi utilizado para facilitar a coleta de informações e dados do questionário, simplificando a leitura de resposta dos participantes. O link do questionário foi enviado por e-mail e whatsapp.

Ao utilizar o Estudo de Caso como a metodologia complementar neste estudo, os estudantes (graduandos em EFI) puderam levantar problemas e situações que os estimularam à tomada de decisões doravante em casos reais, fictícios ou adaptados de realidades observadas no ensino médio. As informações principais foram dispostas em gráficos, quadros e tabelas. Mais especificamente, esta discussão se deu pela análise de sequências didáticas elaboradas na disciplina de Prática de Ensino IV - juntamente com os acadêmicos do $4^{\circ}$ período de Licenciatura em EFI - e que se desenvolveu dentre as etapas descritas no Quadro 1:

Quadro 1. Etapas do estudo em campo.

\begin{tabular}{|c|c|}
\hline Ações iniciais & Práticas pedagógicas em campo \\
\hline $\begin{array}{l}\text { - Apresentação dos objetivos e da Proposta de } \\
\text { Trabalho desta Dissertação junto aos Diretores do } \\
\text { Instituto de Educação do Município de Itaperuna } \\
\text { (ISEMI), bem como aos Discentes do } 4^{\circ} \text { Período } \\
\text { do Curso de Licenciatura em Educação Física, } \\
\text { para assinatura dos termos de Consentimento } \\
\text { Livre e Esclarecido e autorizações necessárias. }\end{array}$ & $\begin{array}{l}\text { - Divisão da turma em } 06 \text { (seis) grupos de trabalho, } \\
\text { em que cada equipe teve um tema central para } \\
\text { análise e construção de Práticas Pedagógicas, } \\
\text { sendo: Jogos e Brincadeiras, Danças, Lutas, } \\
\text { Esportes, Ginásticas e Práticas de Aventura. } \\
\text { - Aplicação das atividades em ambiente escolar; } \\
\text { Avaliação em grupo dos dados coletados a partir } \\
\text { das observações de cada membro do grupo de } \\
\text { pesquisa; registradas em relatórios individuais. }\end{array}$ \\
\hline
\end{tabular}

Fonte: Autores (2021).

\section{Resultados e Discussões}

Após as experiências didáticas aplicadas com o auxílio de tecnologias educacionais, no gráfico exibido na Figura 2 , foi possível observar a percepção dos pesquisadores discentes sobre os principais conteúdos que poderiam ser beneficiados por práticas pedagógicas mediadas pelas as TDIC's: 
Figura 2. Percepção dos discentes sobre os principais conteúdos que poderão ser beneficiados por práticas pedagógicas com as TDIC's.

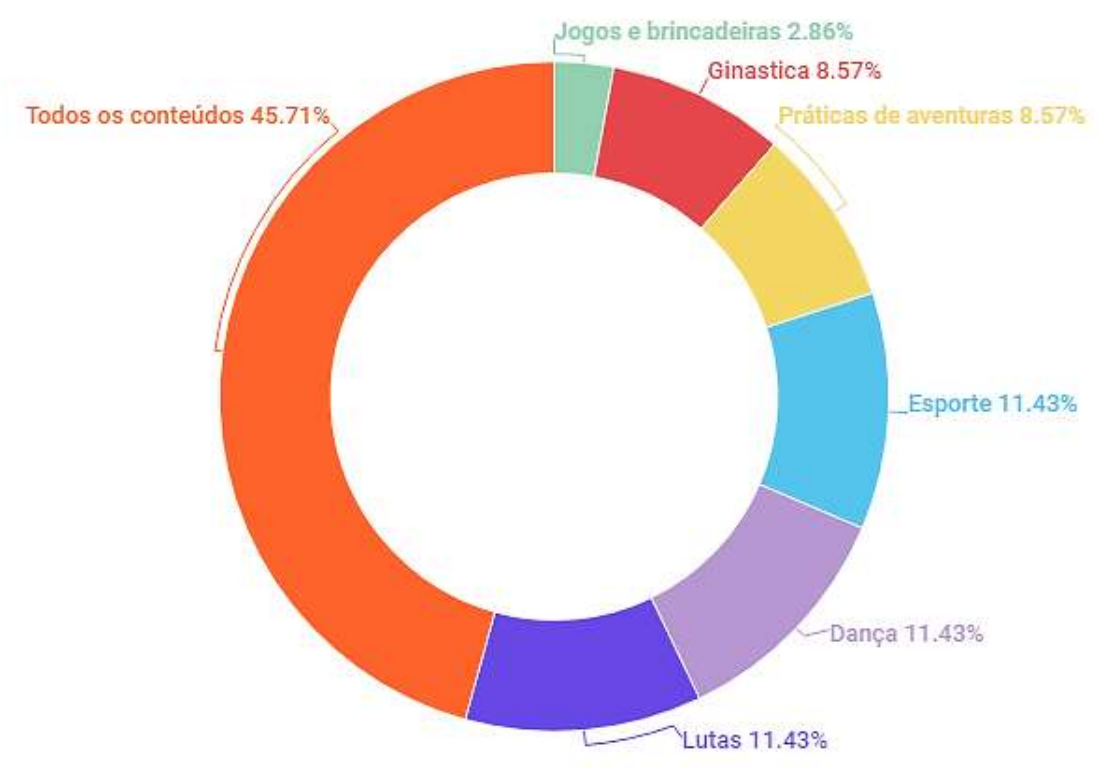

Fonte: Autores (2021).

Conforme apontado pelos dados, $45,71 \%$ dos pesquisadores discentes informaram que todos os eixos temáticos na EFI poderiam ser beneficiados com o uso das TDIC's, sendo que 11,43\% responderam que seria o conteúdo de Lutas, Dança e Esportes - os mais bem atendidos. Neste mesmo cenário, 8,57\% dos pesquisadores responderam que seria o conteúdo de Práticas de Aventura e Ginástica. Apenas 2,86\%dos estudiosos responderam que o módulo de Jogos e Brincadeiras seria o de maior relevância para a mediação com as TDIC's.

A análise dos dados reconheceu que as diferentes práticas corporais poderão ser beneficiadas e mediadas por um ensino auxiliado pelas tecnologias educacionais. Como instrumentos complementares, elas podem trazer maior contextualização, vivências das atividades, e ainda, servirem de suporte teórico para que os docentes promovam um maior aprofundamento sobre as tematizações nas aulas.

Fiel (2020), em seus estudos alerta para possíveis inquietações e reflexões sobre a presença das TDIC's no contexto da EFI. A autora corrobora com o presente estudo quando reconhece a importância e os benefícios que as tecnologias podem trazer para o trabalho com a cultura corporal, aponta que não estamos diante de uma "modinha", porém chama a atenção para as pessoas que não tem acesso às "linguagens tecnológicas" e para o risco da "tecnização" dos corpos que pode ocorrer ao se pensar apenas a máquina como instrumentalizadora e não como potência de construção de saberes corporais.

Na Figura 3 foram apresentadas as principais vantagens da construção de Práticas Pedagógicas permeadas pelas TDIC's no contexto das aulas de EFI. 
Figura 3. Análise resultante dos dados sobre construção de práticas pedagógicas significativas com TICs após observações das sequências didáticas.

\section{Principais vantagens quanto à utilizaçåo das TIC's na EFI}



Fonte: Autores (2021).

Santos, Costa e Alves (2020) informam que a atividade pedagógica mediada pela tecnologia possibilita a simulação e aprendizagens significativas por meio da pesquisa e resolução de problemas para o cumprimento de metas. De acordo com Carneiro (2019), estas podem auxiliar na diversificação de processos avaliativos, inclusive; por meio de metodologias baseadas em resolução de problemas. O que para a EFI tira os conteúdos da mera repetição descontextualizada de movimentos colocando o estudante no centro do processo criativo diversificando e acatando as diretrizes para um pensamento multiculturalista e pós-crítico.

Conforme apontado pelo quadro da Figura 3, a utilização das tecnologias nesta relação pedagógica entre alunos e professores institui um fator de inovação didática, possibilitando novas modalidades de ensino e provocando uma aproximação escolar para com a cultura vigente. Junto da tecnologia, a escola transforma-se de simples transmissora de conhecimentos em organizadora de aprendizagens, proporcionando aos discentes os meios necessários para a ressignificação das informações.

Ao se pensar a presença da informática no contexto da educação e da EFI, é fundamental que as escolas, secretarias de educação e redes de ensino incentivem e promovam formações e capacitação aos professores, em especial, aos de EFI que apresentam formação ainda muito cartesianas e tecnicistas. O diálogo entre a máquina e o docente precisa ocorrer pelo viés científico embasadas em teorias que promovam o enlace entre as potentes oportunidades que as TDIC's podem conferir. Para Nascimento e Gomes (2019), a formação docente com foco na informática educativa surge como essencial para que os professores utilizem adequadamente as tecnologias nas salas de aulas para que os resultados individuais e coletivos sejam contemplados nas escolas. E para isto, as ferramentadas digitais não podem servir apenas para reproduzir informações, mas para criar possibilidades de construir conhecimento colaborativamente.

Desta forma, a partir dos dados coletados com as sequências didáticas avaliadas junto ao cenário escolar, o Quadro 2 apresentou um paralelo sobre as diferentes possibilidades pedagógicas em que a tecnologia poderia oferecer ao contexto das aulas de educação física baseado nas perspectivas instrucionistas e construcionistas associadas ao ensino e aprendizagem das práticas corporais. 
Quadro 2. Abordagens Construcionista e Instrucionista aplicadas ao contexto da EFI.

\begin{tabular}{|c|c|}
\hline Abordagem instrucionista & Abordagem construcionista \\
\hline $\begin{array}{l}\text { - Auxilia no ensino de técnicas de forma mais } \\
\text { eficiente; } \\
\text { - } \text { Proporciona maior repetição de movimentos; } \\
\text { Professor atua como instrutor-técnico; } \\
\text { - } \text { O aluno cumpre ordens e comandos; } \\
\text { - Oferece opinião mais precisa sobre correção } \\
\text { de movimento; } \\
\text { - O professor é quem manuseia o computador } \\
\text { - } \quad \text { Aura dar uma referência motora; } \\
\text { individualizada (Aulas de Concepções } \\
\text { - } \quad \text { Mechadas); } \\
\text { - O aludos mais tecnicistas e cartesianos; } \\
\text { tático; Método ideal para treinamento de } \\
\text { equipes para competição de curto prazo; } \\
\text { Importante quando se deseja ter foco num } \\
\text { único assunto que não gere equívoco e nem } \\
\text { ideias opostas; } \\
\text { Tecnologia para reprodução- Mecanização de } \\
\text { movimento. }\end{array}$ & 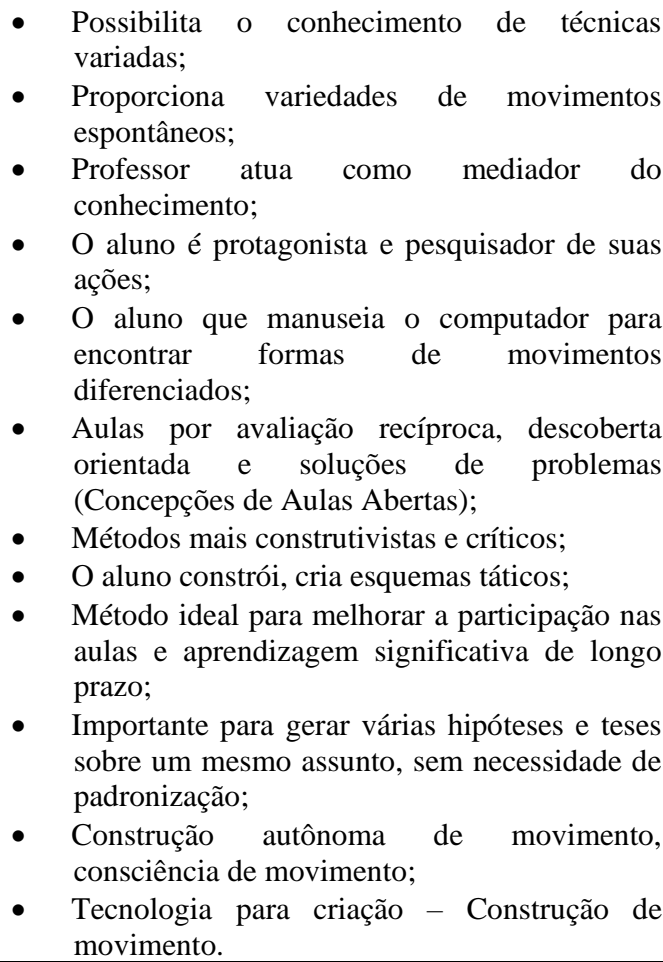 \\
\hline
\end{tabular}

Fonte: Autores (2021).

Da mesma forma que Silva (2020) propõe, o modo construcionista lida com a prática educativa por meio da compreensão do conhecimento discutido dentre a atividade proposta, podendo estar instrumentalizada e mediada pela teoria, e fundamentada na tomada de decisões. Essa transferência da teoria à prática faz uso de pressupostos cotidianos do processo natural de aquisição de conhecimento, como o planejamento e gestão de recursos.

Conforme evidenciada ao longo dos dados desta pesquisa, a finalidade do ensino construcionista é uma educação baseada em parâmetros do ensino ativo. A abordagem pedagógica avaliada implica na necessidade de atividades motoras em que os estudantes manipulem, explorem, interajam com materiais concretos, ao invés de apenas se dedicar a aulas expositivas e ou atividades meramente repetitivas. A possibilidade de ação e reflexão sobre um processo de negociação do conhecimento que hoje é amplamente difundido pela tecnologia - é a característica mais importante da visão construcionista.

Conforme observado pelo registro dos pesquisadores discentes, a metodologia baseada na dinâmica construcionista estimula o potencial criativo dos alunos, de modo a permitir que empreguem a imaginação e o design como ferramentas para solucionar desafios motores propostos. São importantes estratégias para estimular os movimentos espontâneos, busca pelas práticas corporais assistemáticas e o entendimento de que o movimento humano influencia e é influenciado por uma ou mais culturas. Ainda oportuniza a mediação das práticas docentes por métodos de ensino menos centrado no professor, onde na EFI pode-se citar: a avaliação recíproca, a descoberta orientada e a resolução de problemas.

Por outro lado, o uso da tecnologia de forma instrucionista promove o treino do movimento corporal. Nele, o docente se vale de dispositivos tecnológicos para explicar técnicas corporais a partir de modelos sistemáticos por aplicativos, jogos etc. (Carneiro, 2019). Por esta abordagem, pôde-se considerar que as orientações didáticas baseadas no Instrucionismo são eficazes para a repetição e delineamento do movimento corporal com base na assimilação mecanizada sob alguns padrões préestabelecidos.

A abordagem instrucionista é aquela que apenas transmite o conhecimento ao sujeito e de forma expositiva. O 
estudante verifica se compreendeu as informações por meio de exercícios, múltipla escolha e atividades auto corrigíveis pelo sistema que apontam os resultados instantaneamente. Em outras palavras, as práticas pedagógicas instrucionistas trata-se daquelas que fazem uso da explicação de conteúdos em uma comunicação unilateral.

Nesta perspectiva, a prática do professor é baseada na promoção de atividades de memorização e reprodução de informações, sem a demanda de uma exploração ou reflexão sobre o conteúdo trabalhado.

Em uma última análise comparativa é possível sugerir que dentre os modelos didáticos avaliados neste estudo é interessante notar que as práticas pedagógicas que fazem uso dos recursos tecnológicos estão em contínua mudança. Entretanto, embora haja uma classificação clara entre as abordagens instrucionistas e construtivistas, isso não significa compreender que a abordagem instrucionista não contribui à aprendizagem de alunos. Deve-se sempre considerar que o estudante precisa aprender por meios que favoreçam a construção de conhecimentos.

\section{Conclusão}

O objetivo do trabalho foi apresentar a percepção de Estudantes de um Curso de Licenciatura em EFI sobre quais os principais conteúdos que mediados pelas as TDIC's na educação física escolar poderiam apresentar significativos benefícios e vantagens, além de discutir sobre as principais diferenças quanto às Abordagens Instrucionistas e Construcionistas para o ensino das práticas corporais.

Sobre o primeiro apontamento, 45,71\% dos Estudantes de EFI acreditam que todas as práticas corporais podem ser beneficiadas e mediadas pela presença das TDIC's nas aulas de EFI. E, que Lutas, Ginásticas e Danças poderão ser dinamizadas de uma forma mais contextualizada e fácil para ser vivenciada.

Quanto a segunda proposição, observou-se que a Abordagem Construcionista possibilita a simulação, a contextualização e aprendizagens significativas, rompendo com as concepções didáticas mais tradicionais proporcionando alternativas de acesso à informação, construção e a assimilação das informações oportunizando que as práticas corporais possam ir além da métrica e do cartesianismo corporal.

Ao passo que, no que diz respeito à Abordagem Instrucionista, os conteúdos da EFI podem se beneficiar quanto aos seguintes aspectos: automatização do movimento, melhora da técnica corporal, padrão e qualidade técnica e tática, além de se apresentar como importante recurso visual na demonstração das ações corporais podendo substituir a necessidade de o professor ter que saber realizar um determinado movimento.

Em futuras pesquisas, surge, portanto, a necessidade de estudos que rompam com a ideia de que as TDIC's funcionam como suportes, apenas; ou como mecanismos que adicionam suplementos à dimensão técnica/corporal. É fundamental pensar a informática educacional como prática pedagógica, como base didática para tematizar os diferentes assuntos tratados pela EFI.

\section{Referências}

Betti, M. (2007). Educação física e cultura corporal de movimento: uma perspectiva fenomenológica e semiótica. Journal of Physical Education, 18(2), 207217.

Carneiro, C. W. A. (2020). Construcionismo e instrucionismo: pedagogia em diálogo com a modernidade. identidade! 24(2), 69-78.

Faria, J. P. O (2020). Práticas pedagógicas mediadas pelas tecnologias: propostas e desafios no contexto da educação física escolar. Dissertação -Universidade Federal Fluminense (UFF), Santo Antônio de Pádua.

Farias, A. N., \& Impolcetto, F. M. (2021). Utilização das TIC nas aulas de Educação Física escolar em unidades didáticas de atletismo e dança. Revista Brasileira de Ciências do Esporte, 43.

Fiel, P. F. (2020). Educação física e tecnologia: o processo de "tecnização" educacional, Evandro Antonio Corrêa, Dagmar Hunger Curitiba, Appris, 2020.229 p. Dialogia, (35), 288-290.

Gomes, A. A. (2008). Estudo de caso-Planejamento e métodos. Nuances: estudos sobre Educação, 15(16). 
Research, Society and Development, v. 10, n. 16, e89101623399, 2021

(CC BY 4.0) | ISSN 2525-3409 | DOI: http://dx.doi.org/10.33448/rsd-v10i16.23399

Kenski, V. M (2012). Vani Moreira. Educação e Tecnologias: o novo ritmo da informação. Campinas: Papirus, 2008. 144 p. Práxis Educativa (Brasil), 7(1), 285-290.

Macedo, L. M. M., \& Oliveira, N. L. E. (2021). Práticas de Educação Física na pandemia por Covid-19. Ensino em Perspectivas, 2(3), 1-5.

Machado, J. (2020). As contribuições dos recursos tecnológicos na educação física para melhorar o desenvolvimento motor de crianças da fase infantil. https://repositorio.pucgoias.edu.br/jspui/handle/123456789/697

Nardon, T. A., \& González, F. J. (2019). Jogos e brincadeiras: o ensino mediado pelas tecnologias da informação e comunicação. Motrivivência, 31(59), 1-14.

Nascimento, M. C., \& Gomes, G. R. R. (2020). Formação continuada docente para a utilização das TIC no processo de ensino e aprendizagem. Research, Society and Development, 9(2), e33921998-e33921998.

Neira, M. G. (2019). Educação física cultural (Vol. 4). Editora Blucher.

Papert, S. (1994). A máquina das crianças. Porto Alegre: Artmed, 17.

Papert, S. (2001). Education for the knowledge society: a Russia-oriented perspective on technology and school. IITE Newsletter. UNESCO, $\mathrm{N}^{\circ} 1$

Papert, S. (1996). LOGO: Computadores e Educação. São Paulo: Brasiliense.

Santos, B. M. M. da S., dos Santos, M. do S. A., \& da Silva, N. C. M. (2020). Construcionismo e inovação pedagógica. Revista científica do sertão baiano 1(1), 58-66.

Santos, R. S., Costa, D. E., \& Alves, D. B. (2020). O Papel do Professor e do Estudante em Ambiente Construcionista de Aprendizagem. REMATEC, 15, 252265 .

Silva, T. A. (2020). Educação Física Escolar: possibilidades para os cursos de ensino médio integrado do Instituto Federal de Educação, Ciência e Tecnologia de Mato Grosso do Sul-IFMS. Revista Brasileira da Educação Profissional e Tecnológica, 2(19), 9660.

Soares, E. A. A., Prado, M. E. B. B., \& da Silva Dias, F. A. (2020). Formação do professor da educação básica na perspectiva da aprendizagem criativa. Revista e-Curriculum, 18(4), 1879-1894. 